\title{
E-Learning Design Activity to Improve Student's Knowledge and Skills: A Case Study of Database Design Courses
}

\author{
M. Rozahi Istambul
}

\begin{abstract}
Utilization use of e-learning is being increasingly carried out by a number of communities, particularly in the context of education. However, different behavior and in implementing e-learning infrastructure to be implemented, leading to differences in governance in an effort to take advantage of e-learning in their respective educational institutions, such as universities. E-learning actually have a basic philosophy that learning can be done by using information technology. So is the case with conventional learning students and the efforts made by the lecturer to the optimal delivery of teaching materials for learners. It is presumed, can motivate students to independently use a number of learning resource. This paper gives an overview of the rules in using the e-Learning, for a process of increasing the knowledge and skills for learners, and not just only limited to what is conveyed by the lecturer in the direct transfer of knowledge or learning.
\end{abstract}

Index Terms-E-learning, governance, rules, improvement of knowledge.

\section{INTRODUCTION}

The development of information technology is growing rapidly, as well as the utilization of cultural community is also involved, and contribute to the use of information technology capabilities. In the world of education also has a number of problems related to the learners (students), who must do the learning. Learning activities that engage students to be able to receive the knowledge given by the lecturer. The main obstacle happens to students, the ability to understand that knowledge was limited to what is delivered by faculty at each lecture lasts, so the results of these lectures also be less than optimal. The resources of the library is still lacking in demand by a number of students with a variety of classic reasons, ranging from the incompleteness of the library reference books; difficulties to find books that match the problems encountered; does not have a high interest in learning the library; to less excited and motivated to solve problems independently or in groups.

Other conditions, that the problem of the assignment given by lecturer is not always completely resolved; students generally do not have a solution for a settlement outside of the material that has been submitted by the lecturer. Students only learn the case studies provided by lecturers on each weekly topic, so that the knowledge gained only limited transfer of

Manuscript received October 20, 2014; revised December 27, 2014. This work was supported in part by The University of Widyatama Bandung.

M. Rozahi Istambul was with the University of Widyatama Bandung, Indonesia. He is now with the Faculty of Engineering, the Department of Information System, Indonesia (e-mail: rozahi.istambul@widyatama.ac.id). knowledge that has been given by the lecturer at the time was in the classroom.

Actually, the above conditions will always be the case, if the educational institution does not actively think of solutions completion. One can be used as a reference for the completion of this, the use of e-learning. Of course, e-learning designed to be able to give an order and culture in learning, by utilizing information technology to the fullest. Further development of e-learning is not just learning to use an electronic course but it is necessary to build a rule and management of good teaching by using information technology. This is known as the learning management system (LMS), which serves the needs of students in order to design and ease navigation for students to perform learning activities.

The seriousness role of students to learn in this decade is actually very high, especially by combining the growing culture today, such as information technology. Learn equivalent of using the information, wherever and whenever information can be obtained, of course, with the intention to get it because it was accompanied with an easy way to access it. That is, learning should be a student needs but the manner of presentation and its management should require an adjustment to the behavior of students who are fond of using information technology.

The adjustment of these needs can be a way of stepping in the learning experience, the more creative and innovative for the students, if the institution can present it in a more easy and convenient by using e-learning. It is based, that the ability of e-learning tools can provide a variety of solutions and the ease in obtaining a variety of learning resources, as needed by the student or the expected direction of a faculty mentor courses.

\section{Methodology DeVelopment E-Learning}

A variety of things in the design of the e-learning needs to be done, given the philosophy in theory be able to support motivation and learning activities so that students can be comfortable in using e-learning. Here are various references relied upon in the development of e-learning development methodologies in the subject of database design.

\section{A. Learning and Knowledge}

Knowledge is the essence of the human being to be able to understand a situation. Students also interpret this situation in the form of problem solving in the course, which means students have the motivation to be able to understand and solve the problem. The main obstacle in the settlement, that the students are required to master a variety of theories and application of a variety of subjects, while the facility in 
obtaining teaching materials currently in the conventional form.

The lecturer just suggesting, directing, and transferring knowledge to the students in order to understand the information or examples of cases that have been taught, as a result of knowledge and skills of students limited to what has been transferred by the lecturer in class. Limitations of time and place that limit the lecture meeting, causing the formation of conditioning the conventional way of learning.

This condition makes the student is not independent, because they always feel comfortable in the learning process if accompanied by a lecturer. So, anything that is directed and assigned by professors often triggers students to learn independently, meeting facilities already resulted in the design in the form of face-to-face in the classroom that can motivate students to learn.

Much of human knowledge acquired through the eyes and ears, it is strongly influenced by the intensity of attention and perception of the object. Knowledge or cognitive domain is crucial for the formation of a person's behavior [1].

Everyone actually has a way to learn something, such as time and place convenient to learn, so the limitations of time and space facilities should not be an obstacle in obtaining knowledge. Learning is also a conditioning, meaning that conditioned the way in which students acquire knowledge by facilitated student learning appropriate circumstances, would be nice and comfortable. The way this kind of learning can motivate students to complete their lesson thoroughly, because a student can repeat any material that needs further review and controlled. Supposing, students can set when to learn.

The mastery learning model is an attractive method to increase the likelihood of a student being able to achieve the expected level of performance. As the sense of mastery learning, which is a frame of mind in planning the instructional sequence, which is formulated by John B. Carroll and Benjamin Bloom in quotation Nasution [2].

Carroll looked at the talent as the amount of time spent on a particular person to learn the material, and not a person's capacity to master the material. Bloom Carroll transforming view that is if the instruction is processed in this way, Bloom believes that the learning time can be adjusted with the talents of students.

The two views above clearly describes the meaning of learning, that in this case study on e-learning system design should be no learning instruction made by the lecturer, and then students can learn according to their comprehension. That is, there is a gradual attempt made to understand more deeply the students according to their needs, which may be repeating material already studied without loss of information at all.

Teaching individual students is not easy along with the heterogeneity of capabilities and capacities of students in the learning process. Student's learning style influences the effort that must be done to solve the problem of educators that individual.

The instructional design can be built based on the philosophy of constructivism as a pattern of learning in this article was developed using e-learning. Design results will lead to a very high student activity as a student center learning
(SCL). In this case appears, that the students at the center of strategies for learning, while faculty need to be involved in directing the student.

As in writing Siahaan [3], that the principles that are often taken from constructivism include: 1). knowledge is actively constructed by the students; 2). pressure lies in the learning process of students; 3). teaching is to help students learn; 4). pressure in the process of learning more on process and not on learning outcomes; 5). curriculum emphasis on student participation; 6). teacher is a facilitator.

According to Rosenshine in the writings of Bruce Joyce [4] that an effective teacher will ask a lot more questions, and ensure student understanding and to ensure that all students have the opportunity to respond. Of course, if it refers to that proposed by Rosenshine it takes more time for discussion, so that the atmosphere of cognitivism and contructivism on student self can be formed.

\section{B. E-Learning}

According to Tan [5] learning about issues today, in our current educational practices, are we developing students with the Necessary intelligences and capabilities for the $21 \mathrm{st}$ century? What are the challenges facing your current education system?

One form of activity in an e-learning instructional model is individualized learning. The students can learn independently by accessing the information, materials or lessons online via the internet. Not that learning itself but self-learning, is learning initiative with or without the help of others in the study. Thus, as a self-learning can be defined as a method of learning that positions students as responsible, in control, decision or took the initiative in meeting their own learning and achieve success with or without the help of others (see Table I).

TABLE I: ACTIVITY LEVELS OF E-LEARNING

\begin{tabular}{ll}
\hline Activity & \multicolumn{1}{c}{ Objective } \\
\hline Getting the knowledge & The objectives and activities of learning as \\
the basic knowledge acquired by the & student (such as lectures, lecturers \\
& teaching materials, reference / link \\
& material) \\
Exercise and application & The objectives and activities of learning, \\
& mostly in the form of question formats \\
& (such as quizzes, assignments, discussion \\
& forums) \\
Exploring and evaluating & The objectives and activities of the \\
learning done by students to explore & knowledge that has not been taught or \\
lecturer, and active (easily) perform a & variety of roles in the regulation process of \\
Propose and create & Students are required to submit a proposal \\
and a response or producing a new & product, it is related to strategy or logic \\
during the process of solving a problem \\
(such as providing a dilemma situation, \\
the student must analyze, and propose that \\
a problem)
\end{tabular}

E-learning is an approach to learning and development: a collection of learning methods using digital technologies, the which enable, distribute and Enhance learning, by kenneth 
Fee [6]. As also described in the following table regarding the level of learning activities in adopting e-learning, advanced by Richard, Kendra, Yiu [7].

In the development of e-learning requires a number of implementation strategies, considering the condition of the infrastructure of an educational institution somewhere and the state will be different. Much can be done by optimizing the role of educational institutions in e-learning, thus improvement of knowledge on the process of learning can take place for students.

\section{The Stages of Research}

The scope of this research is aimed at students who take courses in the fifth semester, while the subjects were used as a pilot project is the subject of database design. The number of students involved as many as 40 students in one class, while the subjects contracted the advanced courses. Previously, students have received basic courses as a prerequisite the database system.

The study was conducted over 9 weeks e-learning meeting with a number of activities that have been designed to be presented in each week.

The first phase, prior to this e-learning lectures, the student must attend a workshop prior e-learning to provide an understanding of how students learn independently by using the facilities and tools in e-learning. Various activities are described on the importance of the involvement and contribution of students in each week.

The second phase, the lecture will take place using a number of activities that must be followed by every student, which is downloadable teaching materials each week, which aims to ensure students see the beginning of the material to be learned each week.

The third stage, an evaluation to compare students knowledge at the time of initial teaching materials submitted each week for download, how to measure the knowledge of students by providing related to pretest materials that have been downloaded to be studied.

The fourth stage, students can contribute to the discussion forums, which advance his discussion topics presented by faculty adviser concerned subjects. This discussion forum as a means of contributing to students in sharing information or knowledge they gained by way of their understanding, relevant teaching materials and other downloadable resources that can be obtained, such as library books, eBooks, journals, proceedings, or links that provide various information required. The role of faculty adviser in this regard, especially will take comments that are not in accordance with the subject matter or lack of explanation in accordance with the way the final settlement.

The fifth stage, the implementation posttest useful for evaluating the extent of understanding of the students who have been held during the forum took place. This condition is expected to provide new insights for students in a more detailed understanding of teaching materials that have been downloaded previously.

The sixth stage, students work on assignments for a particular week, the scope consists of several previous weekly teaching materials combined. Unlike the posttest based on material tested weekly.
The Seventh stage, a weekly reflection of all the activities that have been carried out weekly. The results of all phases is automatically recorded on each activity, including valuation adjusted interaction models, including a pretest assessment, forums, posttest, and tasks.

\section{ANALYSIS DISCUSSION}

E-learning design in this study can be designed to enhance the knowledge of students in a course database design. The main thing is to be expected in this learning process, that student self-learning process based on the number of rules in the e-learning system. Beside that the student will be directed to understand and find a way of solving the problem.

The role of teaching is not simply to convey information but rather to engage learners in actively constructing knowledge [8]. These conditions are designed, considering the students have learned and how different time in understanding a topic according to his ability. For example, there are students who can grasp the material weekly takes a long time or frequently repeated learning, to a topic compared with other students.

Similarly defined by Jerome S. Bruner, that discovery learning can be defined simply as a learning situation in the which the principal content of what is to be learned is not given, but must be Independently discovered by the learner, making the student an active participant in his learning. All activities are related to science exploration theory and Bruner's theory of discovery quoted by Chen, I-shin. The process of the invention can be common capabilities through problem-solving exercises and practice of forming and testing hypotheses. Meanwhile, according to John W. Santrock [9], the method of discovery learning is learning in which students construct their own understanding.

As a replacement of faculty activities in delivering the material to the students, which is discussed in the forum. The lecturer in this case as the controller of the various comments that appear in the forum. While the student's involvement in the activities of this forum is very high, considering they are required to contribute to deliver a range of findings based on the topics presented by faculty in the relevant week. The results of these findings is that the search must be understood in the way the presentation of learning resources.

As for the variety of learning resources appropriate reference, such as: journal, proceedings, eBooks, and other related links. This finding ways that will inspire the learning of students, or other students are sharing information with each other in discussion forums.

Measurements were carried out to see an increase in student knowledge in e-learning process, there will be a number of tests, the pretest, forums, and posttest on each week and assignments for a particular week. The implementation of the activities carried out after the student pretest downloading materials in weeks running. Furthermore, the students learn the material is further tested for the next day. Then the activity is done by providing a forum for discussion and commentary on topics that are important responses based on the material weeks running. In this discussion forum, the material will be developed along with a variety of perspectives and case studies are discussed according to the results of a search 
finding students. In order to increase student motivation to provide feedback and comments, the lecturers also conduct an assessment of the student at the forum.

According to Nandi, Chang, and Balbo [10], quoting from Tallent-Runnels and Levine, discussion forums that also provide an effective opportunity to exchange ideas and share knowledge amongst learners

According to Anderson [11], using online resources expand the opportunities for students to reflect upon Reviews their thinking and experience the discourse with other students and instructor. It individualizes Reviews their learning experience facilitating the development of deep-level learning and new knowledge structures. Thus, a centralized learning center, centralized assessment, and the content is focused on the students, while the faculty as a steering function of what is being discussed on the forum by learners.

Likewise Rovai research results [12], Suggests grading strategies influence online discussions and can provide Necessary extrinsic motivation for students to Interact. He reports a significant increase is in the number of student messages per week and a concurrent increase is in sense of classroom community discussions for courses in the which accounted for $10-20 \%$ of the course grade Compared to courses in the which discussions were not graded.

Furthermore, insights and cases that develop in the forums and instructional materials that students have acquired, further testing will be done. Posttest is a tool to test the extent to which the increase in student knowledge related to the topic of the week, if there is an increase compared to the previous pretest results. The science camp is founded on the exploration of Bruner Theory. All activities can help students to understand the new concepts, Thus, increasing students' interesting [13], which was also cited by Chen, I-Shin [14].

In certain week's meeting, will be made in the form of essay assignments, as for the material include a mix / scope of the subject of several previous weekly topics, so that students are trained to be able to develop a database design case comprehensively. In order for a meeting the following week may be better than before, then every weekend also conducted surveys and reflection. This activity is conducted to evaluate all the things that have been done during the process of e-learning in the week in question, so that students can provide suggestions and proposals for the next week.

Besides, it is also a reflection is done to give the student the habit of being able to summarize a topic. The importance of the weekly reflection done, in order to monitor the needs and problems that arise in the students learning experience that has been done, as according to Brookfield [15], through the process of critical reflection, one can discover "the ways in the which the dynamics of power invade and distort educational processes."

\section{THE RESUlt OF RESEARCH}

The study was conducted in the span of nine weeks to see an increase in knowledge of the learners. As mentioned at the beginning, that this first model of e-learning has been communicated to the students through workshops. Here are some of the results of the questionnaire and the achievements of the 40 students who will participate e-learning courses for database design.

\section{A. Workshop e-Learning}

Workshop e-learning become the main goal in socialization before e-learning activities performed. In each session of the workshop on the design according to the needs to be run in e-learning, suppose the rule learning or instructional sequence, such as the obligation of faculty and students to interact online. In the workshop session also made efforts to motivate the students, so that they can understand the direction of e-learning models.

Desired goals in this workshop, that the student's behavior can be shaped to be able to adjust to the conditions expected. Through the adjustment process will be repeated (conditioning) at the time of e-learning, it will produce a meaning of an increasingly dynamic knowledge concurrently learning experience does.

The results of the survey on the implementation of e-learning workshop, drawn up based on the 4 options that have been perceived and expected by students, namely: Disagree (D), Less agreed (La), Agree (A), Strongly agree (Sa). Researchers deliberately create 4 options to avoid a neutral choice students. Here are the results of a survey of 40 students who will participate in the e-learning courses database design (see Table II).

TABLE II: SURVEY RESULTS WORKSHOP E-LEARNING

\begin{tabular}{|c|c|c|c|c|}
\hline The question & $\mathrm{D}$ & $\mathrm{La}$ & A & $\mathrm{Sa}$ \\
\hline $\begin{array}{l}\text { Is the e-learning system is an } \\
\text { interesting thing that will help in the } \\
\text { learning process }\end{array}$ & - & $2.5 \%$ & $80 \%$ & $17.5 \%$ \\
\hline $\begin{array}{l}\text { Is the e-learning workshops to } \\
\text { motivate the learning process run } \\
\text { using e-learning }\end{array}$ & - & - & $77.5 \%$ & $20 \%$ \\
\hline $\begin{array}{l}\text { Is the understanding before and after } \\
\text { the workshop e-learning increased } \\
\text { knowledge in the way of learning }\end{array}$ & - & - & $75 \%$ & $25 \%$ \\
\hline $\begin{array}{l}\text { Is the easy enough to understand the } \\
\text { importance of goals and how to use } \\
\text { e-learning system }\end{array}$ & - & - & $70 \%$ & $30 \%$ \\
\hline $\begin{array}{l}\text { Is the e-learning discussion forum } \\
\text { activities will broaden the knowledge } \\
\text { and problem-solving independence }\end{array}$ & - & - & $82.5 \%$ & $17.5 \%$ \\
\hline $\begin{array}{l}\text { Is the the activity for e-learning } \\
\text { quizzes and assignments in a good way } \\
\text { in improving knowledge }\end{array}$ & - & - & $67.5 \%$ & $32.5 \%$ \\
\hline $\begin{array}{l}\text { What are the various ways through the } \\
\text { pretest assessment, forums, quizzes, } \\
\text { assignments, posttest can be used as } \\
\text { standard, so you will be motivated to } \\
\text { develop knowledge }\end{array}$ & - & - & $72.5 \%$ & $27.5 \%$ \\
\hline $\begin{array}{l}\text { I feel confident that it can perform a } \\
\text { variety of rules in e-learning system at } \\
\text { the time of the lecture later }\end{array}$ & - & - & $62.5 \%$ & $37.5 \%$ \\
\hline
\end{tabular}

When observed from the results of a survey conducted after the workshop e-learning, e-learning models appear to be accepted by the students. In general, the use of e-learning 
students agree with this, and in fact there are a number of students who strongly agree with the learning experience as e-learning.

\section{B. Implementation of e-Learning}

The implementation of e-learning is done for 9 weeks, with each week having a number of obligations to be performed by the activities of students. This e-learning although interpreted as free of activity, in the sense that whenever and wherever it should be accessible, but still need your conditioning and limit the implementation of these activities. In the activity for 9 weeks, arranged various activities to be carried out by students, namely:

1) The first week, second, fourth, fifth, seventh, eighth, will perform activities: downloadable teaching materials; pretest; forums; posttest; surveys; and reflection.

2) Week three, six, nine, will do the activity: download teaching materials; pretest; forums; posttest task; surveys; and reflection.

The first activity each week that will be done by students, that are required to download the teaching materials are carried on every day from Monday to Tuesday. Teaching materials is a matter that must be learned by the students to take a pretest on Wednesday.

Furthermore, after following the pretest then began a discussion forum, to discuss a variety of things in teaching materials including solutions from pretest. These activities give students excited because one of the things that are required, so that all students must contribute to the discussion forum. Contributions may be in the form of comments or responses in the sharing of information obtained by each student.

Lecturers in this context as a guide or director, if there is a discussion needs to be a detailed explanation of the solution. Besides, it is also to provide a high motivation for students, that all students will be given for response ratings and the comments that have been given.

The learning experience in this forum has helped the students to improve their knowledge gradually. Students are more confident with a variety of findings, and also indirectly student doing a comparative analysis of the various entries in the forum.

A variety of perspectives of each student on the discussion forum can provide inspiration in solving various problems encountered. They will help each other directly, since every reference is used as reference to be written in the discussion forum, so that every student can be directly traced the source of the text.

Here are the results of improvement of knowledge is referred to in this paper, by measuring the final results obtained by the students each week. For comparison the measurement, that is a precondition pretest acquired knowledge of students, because only gain knowledge of teaching materials provided by the lecturer to be studied. While the discussion forum is a means to increase their knowledge of the learning experience obtained, as described earlier.

Besides, it is also to train students' skills in problem solving, then given assignments for a particular week. The material on this assignment includes meeting the week prior to the week of the assignment. Completion time assignment begins on Friday until Saturday, while the posttest performed on Sunday.

The results of a survey of 40 student assessment data that has followed the course database design using e-learning, such as the following:

\begin{tabular}{lccc}
\multicolumn{4}{c}{ TABLE III: AVERAGE RATING ACTIVITY E-LEARNING THREE ACTIVITY } \\
\hline \hline \multicolumn{1}{c}{ The Weekly Meeting } & Pretest & Forum & Posttest \\
\hline The first & 67,00 & 76,88 & 79,98 \\
The second & 68,13 & 76,93 & 79,96 \\
The fourth & 69,88 & 77,55 & 79,65 \\
The fifth & 70,13 & 78,00 & 79,88 \\
The seventh & 69,75 & 78,63 & 80,31 \\
The eighth & 70,50 & 78,88 & 80,44 \\
\hline
\end{tabular}

When considered in Table III, it can be concluded at any weekly activity with 3 activity, it appears the increase from pretest to posttest. This is supported by the high contribution of the students in a discussion forum that impact assessment is better than pretest posttest.

At weekly meetings for the pretest there also appears to increase the value, except at the seventh meeting of the decrease and increase again in the eighth meeting, while the value is increasing every week posttest. It can be concluded, that in the very first students to learn independently seems not a lot of experience gained, but after doing the sharing of information on the forums led to improvement of knowledge the student concerned (see Table IV).

TABLE IV: AVERAGE RATING ACTIVITY E-LEARNING FOURTH ACTIVITY

\begin{tabular}{lcccc}
\hline \hline The Weekly Meeting & Pretest & Forum & Assignment & Posttest \\
\hline The third & 68,75 & 77,12 & 81,75 & 81,90 \\
The sixth & 70,50 & 78,38 & 82,00 & 82,50 \\
The ninth & 70,75 & 79,38 & 80,88 & 82,31 \\
\hline \hline
\end{tabular}

While in the weekly activities involving four activities, it seems the average value obtained posttest quite high compared with the average posttest on three activities. This is reasonable, considering the addition of one activity that affects the material is repeated often in the form of training, so that students more easily understand the problems and the completion of a topic (see Table V).

TABLE V: Average RATING ACTIVITY E-LEARning PRETEST - POSTTEST

\begin{tabular}{ccc}
\hline \hline The Weekly Meeting & Pretest & Posttest \\
\hline The first - The ninth & 69,49 & 80,78 \\
\hline \hline
\end{tabular}

On the average value obtained from the overall activity within 9 weeks, that there is an increase in student knowledge acquired based on the comparison with the pretest posttest measurements. It appears, that in the beginning the students have an average value of 69.49 and 80.78 be increased in the posttest. This means that there is an increase in value of 11.29 points.

At the end of the week, always given reflection and learning about e-learning surveys that have been done. The purpose of this activity is to be able to prepare the way of presenting the material and technical interactions that need to be improved for the next week. This activity also provides an opportunity for students to be able to reflect on the topic of every activity that has been carried out, in order to impart skills to the 
students in summarizing a topic of discussion based on the perspective of each student.

The survey is based on four options that have been made by students, namely: disagree (D), less agreed (La), agree (A), strongly agree $(\mathrm{Sa})$. Researchers deliberately create 4 options to avoid a neutral choice students. Here are the average results of the opinion survey for the implementation of e-learning students (see Table VI),

TABLE VI: SURVEY OPINION AVERAGE STUDENT DURING EXECUTION E-LEARNING

\begin{tabular}{|c|c|c|c|c|}
\hline The question & $\mathrm{D}$ & $\mathrm{La}$ & A & $\mathrm{Sa}$ \\
\hline $\begin{array}{l}\text { Is the lecturers presenting instructional } \\
\text { materials of various forms of file }\end{array}$ & - & - & $95 \%$ & $5 \%$ \\
\hline $\begin{array}{l}\text { In the discussion forum, the discussion } \\
\text { topics are very diverse and helped my } \\
\text { understanding of the teaching } \\
\text { materials that have been downloaded }\end{array}$ & - & $2.5 \%$ & $92.5 \%$ & $5 \%$ \\
\hline $\begin{array}{l}\text { The topics are distributed in the } \\
\text { discussion forum, so help provide } \\
\text { insight and understanding of the topic } \\
\text { of the week running. }\end{array}$ & - & $2.5 \%$ & $90 \%$ & $7.5 \%$ \\
\hline $\begin{array}{l}\text { Comments and responses in discussion } \\
\text { forums provide a positive response to } \\
\text { me, to get involved in the forum }\end{array}$ & - & - & $87.5 \%$ & $12.5 \%$ \\
\hline $\begin{array}{l}\text { I also tend to have their own point of } \\
\text { view to solve the problems by } \\
\text { comparing all responses in the forums }\end{array}$ & - & - & $92.5 \%$ & $7.5 \%$ \\
\hline $\begin{array}{l}\text { I can easily repeat the learning } \\
\text { experience by tracking various } \\
\text { information ever presented each week. }\end{array}$ & - & - & $95 \%$ & $5 \%$ \\
\hline $\begin{array}{l}\text { Knowledge of the various sources of } \\
\text { information on the website address, } \\
\text { journaling, eBook, proceedings, } \\
\text { related to the weekly topics can be } \\
\text { found easily }\end{array}$ & - & $5 \%$ & $90 \%$ & $5 \%$ \\
\hline $\begin{array}{l}\text { A variety of evaluations conducted in } \\
\text { e-Learning can provide the motivation } \\
\text { of the acquisition of knowledge that I } \\
\text { have gained }\end{array}$ & - & $7.5 \%$ & $87.5 \%$ & $5 \%$ \\
\hline $\begin{array}{l}\text { The use of e-Learning every week can } \\
\text { improve my knowledge and skills to } \\
\text { understand the weekly topic. }\end{array}$ & - & $2.5 \%$ & $92.5 \%$ & $5 \%$ \\
\hline $\begin{array}{l}\text { E-Learning process is able to increase } \\
\text { the motivation of self-reliance in the } \\
\text { way of learning and the learning } \\
\text { experience. }\end{array}$ & - & - & $95 \%$ & $5 \%$ \\
\hline
\end{tabular}

From the survey results, it appears that the utilization of e-learning, may be a means to enhance the knowledge of students in the subject of database design. In general, students agreed with the presentation and sharing of information related e-Learning weekly topic. Besides, there is also very much agree with the use of e-Learning in facilitating learning and learning experiences in the subject of database design.

However, there are still some students who do not agree with this conditioning, in view of the student once asked the main issue, that connection to access from where inadequate and cause discomfort involved in a number of activities, particularly the completion time of the pretest, tasks, and posttest were already specified deadlines.

\section{CONCLUSION}

Currently e-learning has been used by educational institutions, but the variety of ways in practice that makes the difference. It becomes apparent, given the differences in the infrastructure and culture of the environment of an educational institution that will affect the way the implementation of an e-learning.

It, too that occurs in the discussion in this e-learning research paper, which needs to design it first needs to be used in the application of e-learning. A variety of considerations were made and a milestone in implementing e-learning activities, such as the policy of the party leadership and the owner; rules in interacting in e-learning; socialization; and a number of parameters measurement and assessment survey, to be able to perform actions related to the implementation of e-learning controlling these.

Methods of improvement of knowledge on database design courses; it can be used as a reference for the application of other subjects. However, it should be conditioned and are considered first, regarding the opportunity to do for all parties, including the types of courses that fit the pad presented e-learning, especially students involved in the subject concerned.

\section{ACKNOWLEDGMENT}

Awarded a grant from the Ministry of Education and Culture Directorate General of Higher Education, Directorate of Education and Student Affairs, regarding the study "Development of Instructional Model of Non - Conventional ICT based in 2013".

\section{REFERENCES}

[1] S. Notoadmojo and K. M. I. D. Seni, Jakarta: Rineka Cipta, 2007, pp 143-146.

[2] S. Nasution, Berbagai Pendekatan Dalam Proses Belajar \& Mengajar, Sinar Grafika Offset, 2011.

[3] S. Sudirman, "E-learning (Pembelajaran elektronik) sebagai salah satu alternatif kegiatan pembelajaran," Jurnal Pendidikan, p. 42, 2002.

[4] B. Joyce, M. Weil, and E. Valhoun, Models of Teaching, Eighth edition, Pearson Education, 2009.

[5] O. S. Tan, Problem Based Learning Innovation - Using Problems to Power Learning in the 21 st Century, Thomson, 2003.

[6] F. Kenneth, Delivering e-Learning: A Complete Strategy for Design, Application, and Assessment, London: Philadelphia, 2009.

[7] R. W. C. Lui, K. K. Y. Lo, and S. M. Yiu, "Evaluating and adopting e-learning platforms," International Journal of e-Education, e-Business, e-Management and e-Learning, vol. 3, no. 3, June 2013.

[8] R. Al-Mahmood and C. McLoughlin, "Re-learning through e-learning: Changing conceptions of teaching through online experience," in Proc. ASCILITE Perth beyond the Comfort Zone, 2004.

[9] J. W. Santrock and J. P. Pendidikan, Jakarta: Kencana, 2008.

[10] N. Chang and Balbo, "A conceptual framework for assessing interaction quality in online discussion forums," in Proc. ASCILITE Auckland.

[11] T. Anderson, "Towards a theory of online learning," in T. Anderson and F. Elloumi (Eds.), Theory and Practice of Online Learning, Athabasca University Press, pp. 33-60.

[12] A. P. Rovai, "Strategies for grading online discussions: Effects on discussions and classroom community in Internet-based university 
courses," Journal of Computing in Higher Education, vol. 15, no. 1 , pp. 89-107, 2003.

[13] L. C. Gregorio, "Bringing science to everyone: Achieving scientific and technological literacy for all," presented at the ICASE International Workshop on Promoting Scientific and Technological Literacy through Science Toys and Out-of-School Science Activities, Pattaya, Thailand, April 4-7, 2005.

[14] I. S. Chen, "The study of sience concepts and science attitude for science camps in Taipei elementary schools," 2013.

[15] S. D. Brookfield, Becoming a Critically Reflective Teacher, San Francisco: Jossey-Bass, 1995.

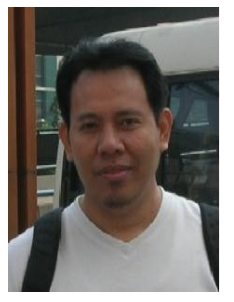

M. Rozahi Istambul was born on October 14, 1967 in the city of Makassar, South Sulawesi, Indonesia Education is taken at the undergraduate level, in 1992 at the High School Science and Technology Indonesia Bandung, majoring in informatics engineering. Then, he continued the master's level education, the field of information systems and graduated in 2002. Today, he is currently completing his doctoral program at the dissertation in Indonesia University of Education, in study programs curriculum development, a special field of information technology education. He joined IACSIT. He worked as the head of study programs information systems at the University Widyatama, Bandung. Besides, it is also as the responsible of e-learning the scope of the University Widyatama Bandung. Researchers are also often involved in society service weather activities, which continue to be developed by building the use of information technology in a number of small medium micro enterprises (SMEs) in the Bandung City.

Mr. Rozahi is a member of the Association of Indonesian Computer University (APTIKOM), as well as a member of the International Association of Engineers (IAENG), and a member International Economics Development Research Center (IEDRC). 